\title{
Effects of Climate Change on Heat Accumulation and Precipitation in Thailand
}

\author{
W. Jinsart and S. Thepanondh
}

\begin{abstract}
The impact of future climate change on heat accumulation and precipitation in Thailand were simulated by the regional circulation model (RCM) in SIMCLIM system. The model was run under four Special Report on Emission Scenarios (SRES) A1B, A1FI, A2 and B1. The temperature variability in regional scales was analyzed using the observed daily data from 1951 to 2011 . The year 1992 was used as a base year in this analysis. The heat accumulation, in 2042 was increased $14 \%, 15 \%, 12 \%$ and $11 \%$ and in 2092 was increased $33 \%, 49 \%, 41 \%$ and $22 \%$ for $\mathrm{A} 1 \mathrm{~B}, \mathrm{A1FI}, \mathrm{A} 2$ and $\mathrm{B} 1$ scenarios, respectively. The precipitation was simulated using the year 2012 as a base year. The increase precipitation in June, for worst case A1F1 was $3.42 \%$ in 50 years and $5.85 \%$ in 100 years. In A1B1 with taking care of global warming, the precipitation in June will increase $2.67 \%$ in 50 years and $3.93 \%$ in 100 years.
\end{abstract}

Index Terms-Climate change, heat accumulation, precipitation, Thailand.

\section{INTRODUCTION}

Climate variability is very important for agriculture. Even the slightly changing of weather conditions could have the effect to the productivity. There are many studies on climate change impact model found the evidence of the association between crop yield and global warming [1]-[3].

Thailand, as a big rice production country, should prepare the impact data for the future warming climate adaptation. From the literature reports in next 50 and 100 years, the average temperature overall Thailand will gradually increase and the average precipitation will potentially decrease [4]. However, there are variations of temperature and precipitation in the different regional areas therefore we attempted to predict the future crop yield related parameters, heat accumulation and precipitation in this study.

\section{MeTHOD}

Heat accumulation and precipitation in Thailand were simulated by the regional circulation model (RCM) in SimCLIM system. The standard GCM pattern of temperature change with high sensitivity was applied in the model simulation. The ensemble method was used to construct the

Manuscript revised October 15, 2013; revised December 18, 2013. This work was supported by The National Research University Project of CHE and the Ratchadaphiseksomphot Endowment Fund (CC307A) and National Research Council of Thailand grant 2013-2014.

W. Jinsart is with the Department of Environmental Science, Faculty of Science, Chulalongkorn University, Bangkok 10330 Thailand (e-mail: jwanida@chula.ac.th).

S. Thepanondh is with the Department of Sanitary Engineering, Faculty of Public Health, Mahidol University, Bangkok 10400 Thailand (e-mail: sarawut.the@mahidol.ac.th). future climate change scenarios to address the key uncertainties of GCM projections. For a specific atmospheric state, an ensemble of possible values was generated for the prediction following the 20 general circulation model (GCM) climate change patterns. This relative change pattern or normalized pattern is preferable to averaging GCM outputs because it controls for differences in climate sensitivity across models.

\section{A. Model Description}

SIMCLIM is a computer-based modeling system for examining the effects of climate variability and change over time and space. It is a customized GIS which includes tools for the spatial analysis of climate variability and change and associated impacts on various social-economic sectors. The users can customize the model for their geographical area and spatial resolution and to attach impact models. With the program, the sensitivity analysis and examine sector impacts of climate change can be conducted as well as the integrated impact analysis at various scales.

\section{B. Emission Scenarios}

The most accessible scenarios on GHG Emissions are from the Intergovernmental Panel on Climate Change (IPCC) Special Report on Emissions Scenarios (SRES). These scenarios were used in the IPCC Fourth Assessment Report (AR4) analyses. The business as usual scenario or SRES A1 corresponds to the highest emission associated with the highest temperature change, while SRES B1 corresponds to the lowest. These scenarios correspond to a range of approximately 540-970 ppm of carbon dioxide in the atmosphere in 2100 [5]. Four emission scenarios with different climate sensitivities, A1B A1F A2 and B1 were used in this study. The worst case scenario A1F1 was assumed rapid economic growth, population peak and unlimited fossil fuel supplies. The best case, B1 was the best condition for environmental sustainability.

\section{RESULTS AND DISCUSSION}

\section{A. Heat Accumulation}

The measure of accumulated heat is known as physiological time or thermal time which is often expressed and approximated in units called degree-days. The calculations of this parameter are based on the area under the diurnal temperature curve and between the thresholds. For a site with maximum and minimum temperatures data available, the different methods for calculating degree-days are single sine, double sine, single triangle, and double triangle. All of these are linear methods because the rate of development is presumed to be a straight line directly related 
to temperature [6], [7]. In SIMCLIM impact model, a spatial model calculated degree day from monthly mean temperature data and a site specific model calculated degree day from daily time series of maximum and minimum temperatures. From our results, heat accumulation in the central area of Thailand was found increasing with the global warming GCM pattern, in various scenarios (A1B, A1FI, A2 and B2). The north east of Thailand was become a risk area of increasing the accumulation areas, Fig. 1 . The $\%$ increase of heat accumulation was related to the emission scenarios, Table I. In 2042 heat accumulation was increased 14\%, 15\%, $12 \%$ and $11 \%$ and in 2092 was increased 33\%, 49\%, 41\% and $22 \%$ for A1B, A1FI, A2 and B1 scenarios, respectively. Under the B1 scenario, heat accumulation was predicted to be increased up to about $22 \%$ from the base year 1992. SRES A1F1, heat accumulation was highest and nearly 50\% increase in next 100 years due to global warming.
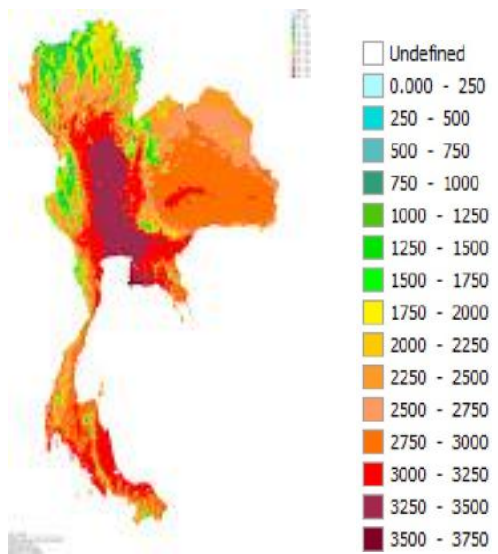

(a) BAU 2042
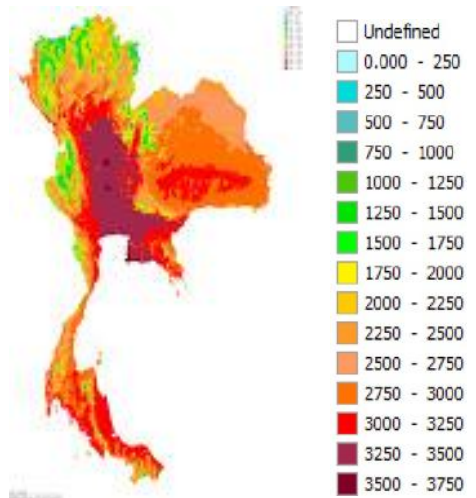

(b) A1F1 2042

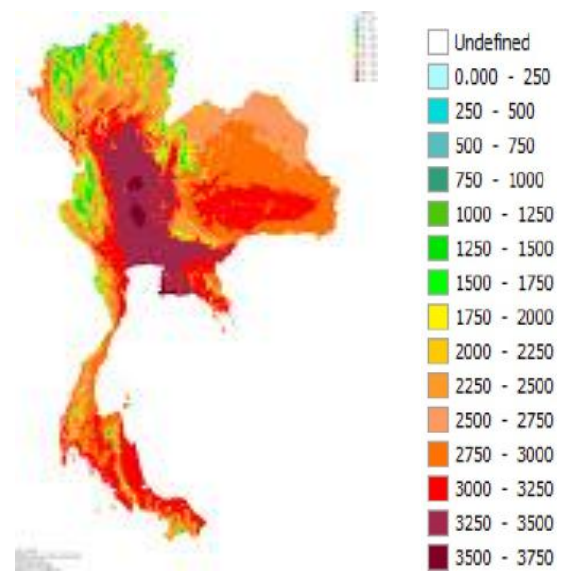

(c) B1 2042

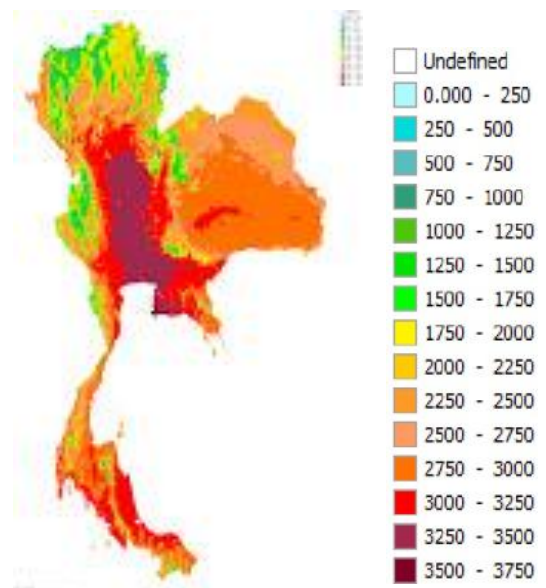

(d) BAU 2092

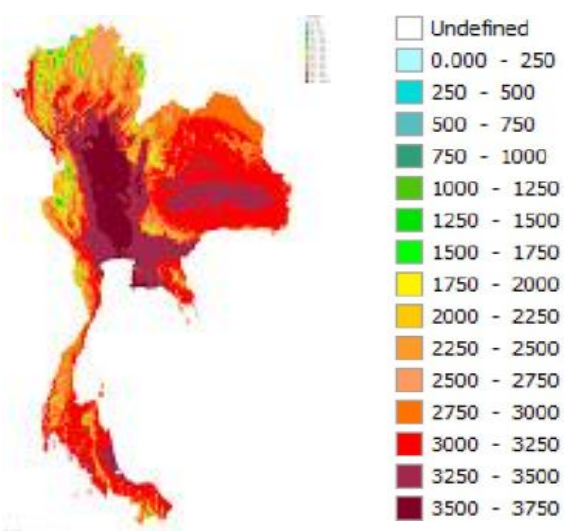

(e) A1F1 2092

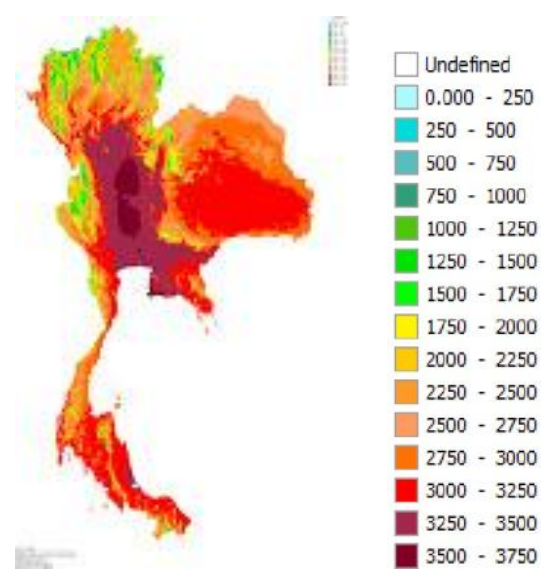

(f) B1 2092

Fig. 1. Comparison of future Heat accumulation distribution 2042-2092 in Thailand in different scenarios; Business as usual (BAU); (a), (d), worst case A1F1; (b), (e) and best case B1; (c), (f).

TABLE I: HEAT ACCUMULATION IN NEXT 50 YEARS AND 100 YEARS (FROM YEAR 1992)

\begin{tabular}{lllll}
\hline \hline Scenarios & $\begin{array}{l}\text { Heat accu. } \\
\text { degree-day } \\
\text { Year 2042 }\end{array}$ & $\begin{array}{l}\text { Y Increase } 2042 \\
\text { Year accu. }\end{array}$ & $\begin{array}{l}\text { Hegree-day } \\
\text { Year 2092 }\end{array}$ & $\begin{array}{l}\text { Increase } \\
\text { Year 2092 }\end{array}$ \\
\hline A1B & 2602 & 14 & 3037 & 33 \\
A1F1 & 2629 & 15 & 3391 & 49 \\
A2 & 2574 & 12 & 3203 & 41 \\
B1 & 2523 & 11 & 2770 & 22 \\
\hline \hline
\end{tabular}

\section{B. Precipitation}

The precipitation distribution and prediction have been 
studied in many regions, particularly for agriculture application [2]-[8]. For model development, C. Yin et al., 2010 used statistical downscaling method to simulate precipitation distribution maps over southeast Australia [9]. They simulated local precipitation for each downscaling precipitation grid for the validation period 1988-2008 to test their model quality. Y. Li and W. Ye, 2011 used GCM output with ensemble pattern to correct the uncertainty on precipitation intensity indices at regional scale [10]. In this study, with SIMCLIM,GCM outputs were used as lateral boundary conditions to drive regional climate models (RCMs) together with 21 ensemble patterns. The monthly simulation of precipitation was run using the year 1992 as the baseline. The input observed precipitation data were obtained from Thai Meteolorogy Department. The annual precipitation simulation did not show the significant changing with various scenarios. However when we analyzed data monthly, we found season variations effect to the distribution. The monthly precipitation distribution in the country is different. The driest month is in April with some tropical rain in the south peninsular and the beginning of the growing crop or the start of wet season in May and June. The distribution and amount of rain in these three months in baseline year 2012 were compared in Fig. 2. In April and May with all tested scenarios, the precipitation significantly decreased but in June was increased from the baseline year.

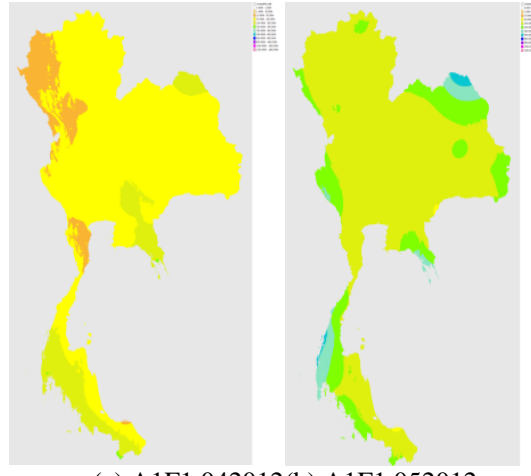

(a) A1F1 042012(b) A1F1 052012

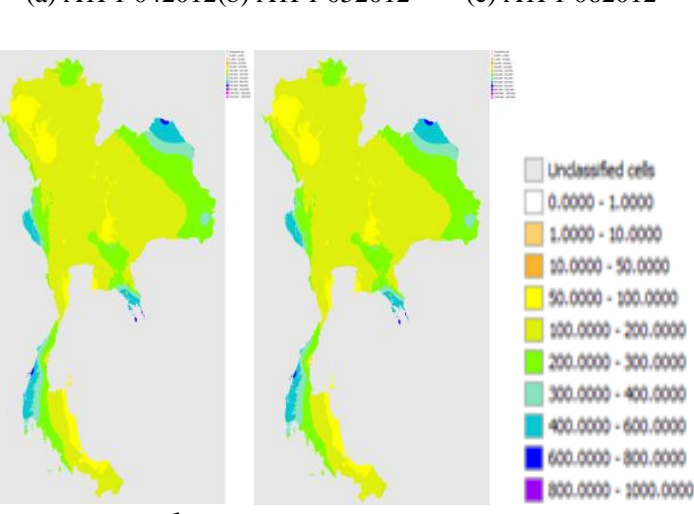

(d) A1B1 062012

(e) B2 062012

Fig. 2. Comparison of monthly precipitation (mm/day) in 2012.

The comparison of worst case A1F1 in April was shown in Fig. 3. There will be less precipitation in the future than in the baseline year 1992, particularly in the west and northwest of Thailand. The precipitation $\mathrm{mm} /$ day and \% change in 5 different emission scenarios (A1B1 A1F1 A2 B1 and B2), were summarized in Table II. The prediction of future precipitations in next 50 years and 100 years were compared. The increase precipitation in June, for worst case A1F1 was
$3.42 \%$ in 50 years and $5.85 \%$ in 100 years. In A1B1 with taking care of global warming, the precipitation in June will increase $2.67 \%$ in 50 years and $3.93 \%$ in 100 years.

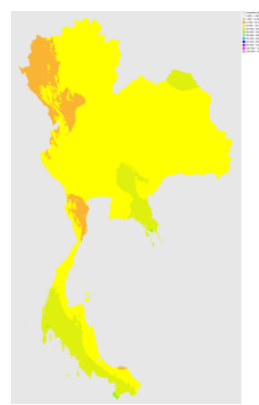

(a) A1F1 042012

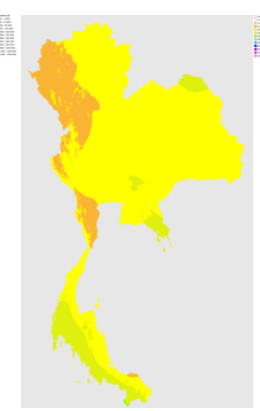

(b) A1F1 042062

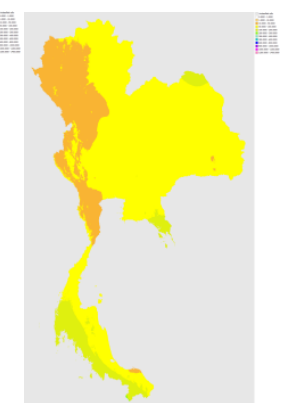

(c) A1F1 062100
Fig. 3. The Comparison of predicted precipitation ( $\mathrm{mm} /$ day) in April in worst case A1F1 in next 50 years and 100 years (scale color as in Fig. 2).

TABLE II: PRECIPITATION (MM/DAY) AND \% CHANGE FROM BASELINE DATA

\begin{tabular}{cclllc} 
Scenario & Apr-2012 & May-2012 & June2012 & June2062 & June2100 \\
& & & & & \\
\hline Baseline & 79.03 & 184.39 & 183.55 & 183.55 & 183.55 \\
A1B1 & 77.89 & 183.75 & 184.51 & 188.45 & 190.76 \\
& $(-1.44 \%)$ & $(-0.35 \%)$ & $(0.52 \%)$ & $(2.67 \%)$ & $(3.93 \%)$ \\
A1F1 & 77.83 & 183.73 & 184.56 & 189.83 & 194.28 \\
& $(-1.51 \%)$ & $(-0.36 \%)$ & $(0.55 \%)$ & $(3.42 \%)$ & $(5.85 \%)$ \\
A2 & 77.81 & 183.72 & 184.58 & - & - \\
& $(-1.54 \%)$ & $(-0.36 \%)$ & $(0.56 \%)$ & & - \\
B1 & 77.86 & 183.75 & 184.53 & - & - \\
& $(-1.48 \%)$ & $(-0.35 \%)$ & $(0.53 \%)$ & & - \\
B2 & 77.77 & 183.7 & 184.63 & - & \\
& $(-1.59 \%)$ & $(-0.37 \%)$ & $(0.59 \%)$ & & - \\
\hline \hline
\end{tabular}

\section{CONCLUSION}

The results indicated Thailand future climate change will potentially affect on crop-yield parameters, heat accumulation and precipitation. Flood and drought areas could also increase. Climate change adaptation and related crop species could be focused in future researches.

\section{ACKNOWLEDGMENT}

The authors are deeply appreciated the observation data from Meteorological Department Thailand. Thank you for the valuable suggestion from SIMCLIM research group.

\section{REFERENCES}

[1] S. Peng et al., "Rice yields decline with higher night temperature from global warming," PNAS, vol. 127, pp. 9971-9975, July 2004.

[2] M. Wang, Y. Li, W. Ye, J. F. Bornman, and X. Yan, "Effects of climate change on maize production, and potential adaptation measures: a case study in Jilin Province China," Clim. Res., vol. 46, pp. 223-242, July 2011.

[3] Y. Li, W. Ye, M. Wang, and X. Yan, "Climate change and drought: a risk assessment of crop-yield impacts," Clim. Res., vol. 39, pp. 31-46, July 2009.

[4] Thailand's First Assessment Report on Climate Change, Thai Research Fund documents, 2011, pp. 242.

[5] Intergovernmental Panel on Climate Change (IPCC), Climate Change 2001, Cambridge University, pp. 881, 2001.

[6] G. L. Baskerville and P. Emin, "Rapid Estimation of Heat Accumulation from Maximum and Minimum Temperatures," Ecology, vol. 50, no. 3 pp. 514-517, May, 1969. 
[7] L. T. Wilson and W. W. Barnett, "Degree-Days: An Aid in Crop and Pest Management," California Agriculture, vol. 37, pp. 4-7, 1983.

[8] M. Tadross et al., "Growing-season rainfall and scenarios of future change in Southeast Africa: implications for cultivating maize." Clim. Res., vol. 40, pp. 147-161, 2009

[9] C. Yin, Y. Li, W. Ye, J. F. Bornman, and X. Yan, "Statistica downscaling of regional daily precipitation over southeast Australia based on self-organizing maps," Theor. Appl. Climatol., 2010

[10] Y. Li and W. Ye, "Applicability of ensemble pattern scaling method on precipitation intensity indices at regional scale," Hydrol. Earth Syst. Sci. Discuss., vol. 8, pp. 5227-5261, 2011

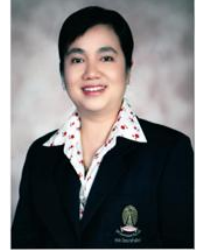

Wanida Jinsart was born in Bangkok in 1960. She received B.Sc. in chemistry and then started working at Chulalongkorn university in 1982 . With part-time study, she got M.Sc. Chemistry from Chulalongkorn university then she got the scholarship for postgraduate study in La Trobe University, Melbourne, Australia. Her Ph.D. in chemistry and biochemistry was granted in 1992.

In 1997, she had worked at Teikyo University, Japan as a research fellow. She had gained the experiences in air pollution and environmental epidemiology research. Her current job position is an Associate Professor in Environmental Science department, Faculty of Science, Chulalongkorn University.

Dr. Jinsart is an active member of Air and Waste Management Association. 